OPEN ACCESS

Edited by:

Joanna Cichy,

Jagiellonian University, Poland

Reviewed by:

Jarek T. Baran,

Jagiellonian University Medical

College, Poland

George Bertsias,

University of Crete, Greece

*Correspondence:

Trine N. Jørgensen jorgent@ccf.org

†These authors have contributed equally to this work

Specialty section

This article was submitted to Cytokines and Soluble Mediators in

Immunity,

a section of the journal

Frontiers in Immunology

Received: 05 March 2020

Accepted: 19 May 2020

Published: 23 June 2020

Citation:

Jones JM and Jørgensen TN (2020)

Androgen-Mediated Anti-inflammatory

Cellular Processes as Therapeutic

Targets in Lupus.

Front. Immunol. 11:1271.

doi: 10.3389/fimmu.2020.01271

\section{Androgen-Mediated Anti-inflammatory Cellular Processes as Therapeutic Targets in Lupus}

\author{
Jessica M. Jones ${ }^{1 \dagger}$ and Trine N. Jørgensen ${ }^{2 \star t}$ \\ ${ }^{1}$ Cleveland Clinic Lerner College of Medicine of Case Western Reserve University, Cleveland, OH, United States, \\ ${ }^{2}$ Department of Inflammation and Immunity, Cleveland Clinic, Lerner Research Institute, Cleveland, OH, United States
}

Systemic Lupus Erythematosus (SLE), among many other auto-immune diseases, is known to be more prevalent in females than in males. This observation has served as the foundation for studies into how sex hormones may interact with the immune system to either drive or inhibit immune activation. Early studies using castration in lupus mouse models showed the potential protective effect of testosterone against lupus development. These studies were later corroborated by observational studies in lupus patients, who upon treatment with testosterone therapy, displayed decreased disease burden. However, there are numerous limitations to treating (especially female) lupus patients with testosterone. Thus, identification of testosterone-targeted cellular and molecular mechanisms affecting immune activation is an attractive target for lupus treatment in the future. Recent studies have examined the effects of androgens on the activation of anti-inflammatory processes. As such, immunoregulatory cell types including myeloid-derived suppressor cells (MDSCs) and regulatory $\mathrm{T}$ and B cells have been shown to be susceptible to manipulation by sex hormones. Here, we review studies of SLE and lupus-like disease in which testosterone or testosterone-derivatives were used to skew an ongoing immune reaction toward an anti-inflammatory state. Via evaluation of both clinical studies and immunologic models we propose new areas for research with the goal of identifying testosterone-driven anti-inflammatory mediators suitable for therapeutic targeting in patients with lupus and other autoimmune diseases.

Keywords: SLE, lupus, androgen, MDSC, pDC

\section{INTRODUCTION}

SLE is an autoimmune disorder which may target multiple organs, including skin, joints, and kidneys. It has an annual incidence of 7.2 per 100,000 individuals a year in the United States (1). Current standard disease management involves the use of glucocorticoids initially, with added maintenance immunosuppressive therapy as needed. These options, however, are broadly immunosuppressive, have significant adverse effects, and do not directly target the cause of lupus.

The pathogenesis of SLE is multi-factorial with genetic as well as environmental factors implicated. Although men with lupus have been shown to have a worse course of disease than women, women are much more predisposed to getting lupus than men, with a 9:1 female to male ratio among patients. Interestingly, this ratio is the highest during reproductive years, when sex hormone levels are the highest. Moreover, disease incidence peaks in women during their 
reproductive years (30-50 years), while in men there is a later peak at ages $50-80$ years (1). This female predisposition is poorly understood in its relation to the pathogenesis of lupus, but suggests that sex hormones play a role in disease initiation or progression. We and others have previously reviewed how sex hormones interact with the immune system in a variety of ways [reviewed in $(2,3)$ ], however our understanding of their specific role in lupus pathogenesis remains limited. Thus, a better understanding of the relationship between sex hormones, cellular and molecular targets of sex hormones, and lupus pathogenesis may lead to new targeted therapies. In this review we will focus on clinical and laboratory studies evaluating the role of androgens in SLE and mouse lupus-like disease (lupus); highlighting potential areas of further study to improve SLE therapies, particularly within testosterone's role as an immune regulator.

\section{ANDROGEN LEVELS AND MANIPULATIONS IN SLE}

Early studies of sex hormone levels in SLE patients showed that female patients with active disease expressed decreased levels of androgens, including testosterone, androstenedione, dehydroepiandrosterone (DHEA), and dehydroepiandrosterone sulfate (DHEAS) $(4,5)$. Decreased levels persisted even after standard of care treatment and the induction of remission (6), suggesting that low levels were not a result of disease, but intrinsic to the patient population. Additional studies of testosterone therapy in SLE patients suggested a benefit from androgen therapy to disease severity (7-9), however a subsequent study failed to show improved disease activity, quality of life or sexual functioning in women with mild/moderate lupus (10). More recently, two larger studies using DHEA at a dose of $200 \mathrm{mg}$ in women with SLE found a higher percentage of patients showing stable or improved disease within the DHEA group compared to the placebo group $(11,12)$. While reasons for the discrepancy in these results remain unclear, it should be noted, that steroid use has been identified as a potential confounder when assessing the efficacy of testosterone $(13,14)$. Thus, further analyses evaluating the clinical efficacy of testosterone and DHEA in SLE patients as a function of steroid use are needed to establish whether such treatments should be more widely offered.

In men with SLE, androgen levels have also been shown to be reduced (15-18), and while an early study showed no evidence of hypogonadism or androgen deficiency (15), a more recent study showed that hypoandrogenism was present in a subset of males with lupus (16). Circumstantially, treatment of male SLE patients with 19-norandrostione resulted in increased serum estrogen levels-and reduced testosterone levels-and elevated serum anti-dsDNA antibodies (18), supporting a correlation between low androgen levels and elevated autoantibodies. Interestingly, a separate study comparing testosterone levels in different patient groups with other chronic diseases also showed reduced levels across all study participants, raising the possibility that low levels of androgens are a result of the chronic inflammatory milieu in all patients and not just in lupus (17).
Finally, sex hormones are altered among transgender patient on hormone therapies. A few case reports exist of male-tofemale transgender patients who developed lupus following the use of feminizing sex hormones (19-21), and a single case report of a female-to-male transgender patient, reported an established subacute cutaneous lupus erythematous prior to hormone therapy with resolution of symptoms following androgen replacement therapy (ART) (22). To our knowledge no reports have been published supporting resolution in maleto-female patients or lupus development in female-to-male patients, further supporting a protective effect of androgens and an exacerbating effect of estrogens. In summary, most studies suggest a possible therapeutic role for androgens themselves, although unwanted side effects have prevented further development of such treatments. Further identification of specific cellular and/or molecular targets of testosterone within the immune system may however represent a promising area for development of future SLE therapies.

\section{ANDROGEN MANIPULATION IN ANIMAL MODELS OF LUPUS}

Given the observations about sex hormones and lupus disease progression in SLE patients, hormone manipulation studies in animal models of lupus have been carried out, primarily using NZB/NZW F1 mice, which have a female predominance for SLE-like disease. These studies, showed a protective role for testosterone in mouse lupus (and a disease promoting role for estrogens), providing a model system in which the cellular targets and mechanisms of action of testosterone can be further studied [reviewed in (3)]. As research with this and other animal models has continued, a number of androgen mediated pathways have emerged as potential future therapy targets, particularly among regulatory cell populations and their activation by androgens.

\section{REGULATORY CELLS AS TARGETS OF ANDROGENS?}

\section{Regulatory T Cells (Treg)}

Regulatory $\mathrm{T}$ cells are represented by the natural thymic Tregs and a population of induced Tregs (iTreg) (23). Support for an association between testosterone and Tregs recently came from a study of children, in which it was found that 8 years old boys with higher levels of cord blood DHT levels at birth expressed increased levels of Tregs as compared with boys with lower levels of cord blood DHT and girls (24). In animal models, however, the literature discussing direct effects of androgens on Tregs is sparse and inconclusive. For example, on one hand it has been shown that testosterone directly affects the expression level of Foxp3 via an androgen-receptor binding motif in the proximal Foxp3 promoter (25), while on the other hand, gonadectomy of male mice in models of virus-induced myocarditis and autoimmune hepatitis resulted in increased or no changes in Tregs, respectively $(26,27)$. In SLE, reduced levels and functions of Tregs have been reported in two independent studies (28, 29 ), while a third study surprisingly showed elevated levels of 


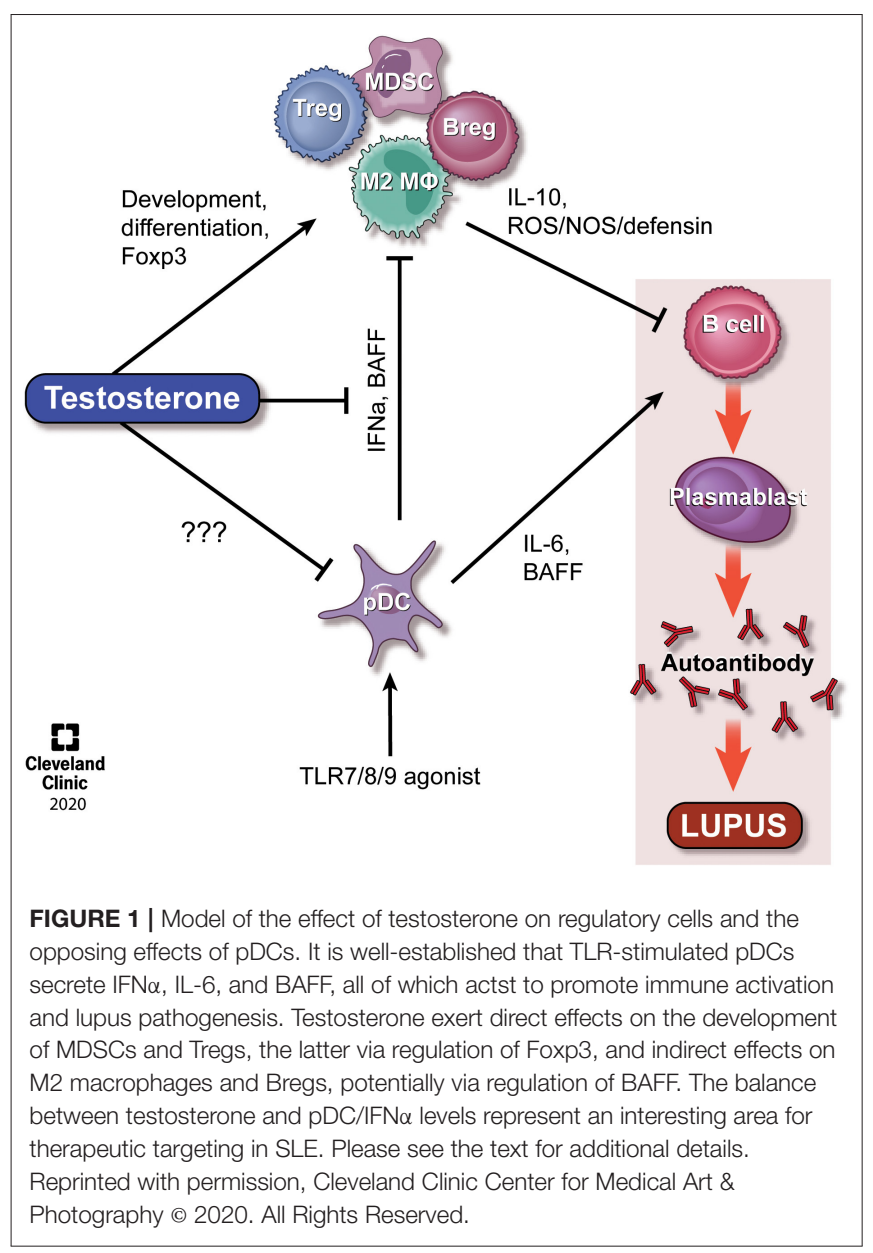

Tregs (30). Interestingly, the latter study also showed that IFN $\alpha$ production from SLE-derived antigen-presenting cells (APCs), but not from healthy control APCs, was responsible for inhibiting Treg functionality (30), suggesting that Treg abnormalities may be a result of elevated IFN $\alpha$ levels and the chronic inflammatory environment of SLE patients (see Figure 1). Therapeutically, adoptive transfer of Tregs in lupus has been investigated. A single lupus patient was treated with autologous Tregs, and the treatment resulted in increased Tregs at cutaneous inflammatory sites, as well as a shift from a Th1 to Th17 response (31). While results from only one patient are difficult to draw any conclusions from, it does support a role for investigating Tregs within the pathogenesis of lupus.

\section{Regulatory B Cells (Breg)}

$B$ cells are known to have a number of actions within the pathogenesis of lupus, most notably the production of autoantibodies. However, a subset of B cells known as Bregs play a suppressive role, mainly through the actions of IL-10 and TGF- $\beta$ and have recently emerged as a focus within lupus (32). In healthy individuals, Bregs have been found to suppress the differentiation of Th1 cells following CD40 stimulation in an IL-10-dependent manner (33). Although Bregs have been found at increased levels in patients with SLE (34), it has also been reported that SLE Bregs are unable to suppress Th1 differentation, and have decreased capacity to produce IL-10 when stimulated with CD40 (33) and TLR9 (35). Interestingly, this dysregulation of Bregs in lupus may be driven through IFN $\alpha$ produced by $\mathrm{pDCs}$, promoting plasmablast differentiation while suppressing Breg differentiation (36) (see Figure 1). Of note, recent drug trials in lupus included testing of compound BT063, a monoclonal humanized anti-IL10 antibody; tested for safety and tolerability. The study met its primary endpoint for safety and tolerability, and additionally showed early signs of efficacy (35). This choice of target is interesting, given the immunosuppressive actions of IL-10, and it remains to be seen whether further studies of this drug will indeed show efficacy, or if a different target within the IL-10 activation pathway may prove to be more appropriate.

While there are no studies, to our knowledge, supporting direct effects of androgens on the development of Bregs, testosterone is known to suppress $\mathrm{B}$ cell expansion in general $(37,38)$, and may hence suppress Bregs as well. Alternatively, testosterone may drive Breg differentiation indirectly via effects of other cells involved in the differentiation and/or maintenance of Bregs. For example, a study by Olsen found that bone marrow stromal cells were required, and mediated the B cell suppressive effects of androgens through TGF- $\beta$ secretion (39). Thus, in this case androgens exerted their effect primarily on pro-B cell populations centrally, with little effect on peripheral cells, potentially redirecting differentiation of $\mathrm{B}$ cells toward a more suppressive phenotype as well. Testosterone have also been found to directly regulate BAFF levels, a key mediator of B cell development and maintenance (40). Using a scleroderma model, Matsushita et al. found that BAFF suppressed Bregs, while a BAFF antagonist reduced $\mathrm{B}$ effector cells but did not significantly alter Bregs (41), thus providing a molecular mechanism for a skewing toward Bregs in males. Further studies are needed to elucidate if other mechanisms also facilitate a role for testosterone in B cell maturation. Belimumab, an antibody against BAFF, is currently FDA approved for lupus and has been shown to have some effect in SLE patients, altering multiple B cell subsets (42). While data specifically on Breg levels before/after treatment have not been reported, there appears to be alterations in expression of some of the markers for Bregs (42). A number of other anti-BLys and anti-APRIL drugs have been studied (Atacicept, Blisibimod, Tabalumab), but have not seen the same level of success (43, 44). There is an ongoing study to investigate the pathways in which BAFF and APRIL act in order to identify specific patient populations that would be ideal candidates for belimumab among lupus patients (NCT03919643). It would be interesting to see if this trial finds any differences in Breg levels and if gender or hormone levels associate with response to therapy.

\section{M2 Macrophages}

Macrophages have diverse phenotypes and can be distinguished as inflammatory M1 macrophages and anti-inflammatory/repair M2 macrophages (45). While M1 macrophages are known to be pathogenic in lupus, recent studies have suggested a role for M2 macrophages in damping the immune response $(46,47)$. As such, adoptive transfer of $\mathrm{M} 2$ resulted in a reduction in SLE severity in a mouse model (48). Therapeutically, PAM3, a TLR2/1 agonist, 
has been shown to skew macrophages toward a M2 phenotype in lupus mouse models (49), however the use of PAM3 as a therapeutic agent is controversial and may likely spike unwanted immune activation.

Testosterone acts on macrophages via androgen receptors $(50,51)$, however few studies have evaluated testosterones effect specifically on M2 macrophages. In one example, Ma et al. found that blocking the androgen receptor alleviated inflammation and promoted M2 polarization in a myocarditis in-vitro model (52). Similarly, a recent study by Zhu found that blocking the AR in renal cells led to decreased kidney stones and increased M2 levels (53), suggesting that androgen receptors exert proinflammatory functions in some disease settings.

Oppositely, among alveolar macrophages (AM) from asthma patients, dihydrotestosterone reduced lung inflammation, and enhanced M2 polarization of AM, despite the finding that M2 macrophages were previously found to correlate with asthma severity (54). While the phenotype of M2s within the alveolar space may not be representative to M2s involved in autoimmune pathologies, the finding suggests that among a more heterogeneous population of $\mathrm{M} 2 \mathrm{~s}$, androgens may play a specific immunosuppressive stimulatory role. Finally, as mentioned above, testosterone reduces BAFF secretion (40) and when the BAFF antagonist BAFF-Trap was used in a rheumatoid arthritis model, animals exhibited reduced numbers of DCs but increased levels of not only Tregs and Bregs, but also M2 macrophages (55). Thus, BAFF, as a key regulator of lupus pathogenesis may affect multiple regulatory pathways, and be regulated in part by testosterone. In summary, the role of androgens in M2 activation/suppression remains unclear and more research is needed to unravel both direct and indirect effects.

\section{Myeloid-Derived Suppressor Cells (MDSCs)}

Myeloid derived suppressor cells are a heterogeneous population of immature myeloid cells, which have been shown to suppress immune functions during inflammatory conditions. The cells have been shown to have deleterious effects on cancer [reviewed in (56)], but may hold therapeutic potential in suppressing autoimmune disorders. However, results on their function in autoimmunity have been conflicting, owing likely to the diverse cell subpopulations included within the population of MDSCs (57).

Using the NZB/NZW F1 mouse model of lupus, we found previously that MDSCs are significantly increased in male mice in a testosterone dependent fashion (58). Moreover, in vitro studies showed that MDSCs were functionally suppressive in postpubertal male, but not female, mice, and that in vivo depletion of these cells resulted in elevated autoantibody production in males, but not females (58). Further analyses showed that $\mathrm{Gr}^{+}$cell-depleted male NZB/NZW F1 mice displayed expanded populations of splenic germinal center B cells, plasma cells and $\mathrm{T}$ follicular helper cells, critical for driving an antibody response, as well as significantly elevated levels of IL-10 $(58,59)$. Subsequent studies by Bird et al. in female NZB/NZW F1 mice corroborated these studies and showed that early depletion of
MDSCs accelerated disease development, while later depletion had no effect (60). Also, a study of the Sanroque mouse model of lupus displayed a similar phenotype with MDSCs inhibiting germinal center B cells, plasma cells and T follicular helper cells, while promoting IL-10-producing B cells (61) (see Figure 1).

MDSCs have been found to be subject to differentiation to pro-inflammatory dendritic cells or macrophages in response to inflammatory cytokines such as TNF $\alpha$, IL-6, and IFN $\gamma(62,63)$. Given the highly inflammatory milieu of female NWB/NZW F1 mice, including elevated levels of serum GM-CSF, IL6 , and IFN $\alpha$, it is possible that naturally occurring MDSCs in female lupus-prone mice are induced to differentiate into effector cells with an immune-stimulatory phenotype $(64,65)$. Alternatively, the inflammatory milieu may promote MDSCdependent extracellular trap formation (and hence MDSC-driven access to nuclear antigens), as suggested by Vlachou et al. (66), although more studies are needed to demonstrate conditions conducive for this change. Interestingly, although studies of MDSCs in SLE patients are few, it has been suggested that MDSCs (as identified by surface markers) from female SLE patients are pathogenic via the production of reactive oxygen species $(64,65)$. No studies have yet specifically evaluated levels of MDSCs in male SLE patients and matched healthy controls.

\section{TESTOSTERONE AND pDC-DERIVED IFN $\alpha$ AS REGULATORS OF IMMUNOSUPPRESSIVE CELLS?}

Similarly to a role for IFN $\alpha$ in inhibiting Tregs and Bregs (see above), IFN $\alpha$-driven IRF7 was shown to negatively control granulocytic MDSC levels (67), suggesting that IFN $\alpha$ blocks MDSC development (see Figure 1). Plasmacytoid dendritic cells (pDCs) are known for their production of IFN $\alpha$ and IL6 and their role during anti-viral responses. Although not uniform among all SLE patients, elevated levels of type I interferons (IFN $\alpha$ ) and the presence of an interferon-stimulated gene signature in PBMCs from SLE patients, further suggest a critical role for pDCs in lupus pathogenesis. Furthermore, IFN $\alpha$ has been implicated a pathogenic role in most animal models of lupus [reviewed in Zhuang et al. (68)] and IL6 have repeatedly been associated with disease incidence and activity in NZB/NZW F1 mice $(69,70)$. Interestingly, production of IFN $\alpha$ and IL- 6 can be induced by the activation of toll like receptors 7 and 9 on pDCs in response to RNA/DNA containing immune complexes (71), commonly found in SLE serum. IL-6 can also be produced by monocytes, and an in vitro study of SLE-derived PBMCs, showed a downregulation of IL-6 production in response to testosterone treatment (72).

As a product of hematopoiesis, pDCs are likely subject to regulation by sex hormones, although to our knowledge, this has not been specifically evaluated in SLE patients. In healthy adults, however, female-derived $\mathrm{pDCs}$ have been shown to produce significantly more IFN $\alpha$ after in vitro TLR7 stimulation than male-derived pDCs, although no difference in the number of these cells was found between the sexes (71). Similarly, in 
vitro studies of pDCs isolated from human infants showed significantly lower IFN $\alpha$ production by male cells than by female cells, a pattern that was even more pronounced if the cells were pretreated with dihydrotestosterone prior to simulation (73).

\section{DISCUSSION}

Overall, our understanding of lupus development has improved over the years, but work remains so that better targeted therapies can be developed. The studies discussed in this review highlight that while testosterone itself is unsuitable as a therapeutic agent, downstream targets of androgens represent de novo areas for research. Given the clear suppressive effects of androgens on the immune system, of particular interest is pinpointing direct steps in lupus pathogenesis at which testosterone acts, as these may ultimately become areas at which to target new therapies that would maximize disease control while minimizing unwanted side effects. Of particular interest is understanding the mechanism(s) through which testosterone affects numbers and functionality of immunoregulatory cells such as MDSCs, Tregs, Bregs, and M2 macrophages to maintain immunosuppression in genetically predisposed male mice. For example, the direct effect

\section{REFERENCES}

1. Gergianaki I, Bortoluzzi A, Bertsias G. Update on the epidemiology, risk factors, and disease outcomes of systemic lupus erythematosus. Best Pract Res Clin Rheumatol. (2018) 32:188-205. doi: 10.1016/j.berh.2018.09.004

2. Taneja V. Sex hormones determine immune response. Front Immunol. (2018) 9:1931. doi: 10.3389/fimmu.2018.01931

3. Gubbels Bupp MR, Jorgensen TN. Androgen-induced immunosuppression. Front Immunol. (2018) 9:794. doi: 10.3389/fimmu.2018.00794

4. Lahita RG, Bradlow HL, Ginzler E, Pang S, New M. Low plasma androgens in women with systemic lupus erythematosus. Arthritis Rheum. (1987) 30:241-8. doi: 10.1002/art.1780300301

5. Folomeev M, Dougados M, Beaune J, Kouyoumdjian J, Nahoul K, Amor B, et al. Plasma sex hormones and aromatase activity in tissues of patients with systemic lupus erythematosus. Lupus. (1992) 1:191-5. doi: 10.1177/096120339200100312

6. Jungers P, Nahoul K, Pélissier C, Dougados M, Athnea N, Tron F, et al. Plasma androgens in women with disseminated lupus erythematosus. Presse Med. (1983) 12:685-8.

7. van Vollenhoven RF, Morabito LM, Engleman EG, McGuire JL. Treatment of systemic lupus erythematosus with dehydroepiandrosterone: 50 patients treated up to 12 months. J Rheumatol. (1998) 25:285-9.

8. van Vollenhoven RF, Park JL, Genovese MC, West JP, McGuire JL. A double-blind, placebo-controlled, clinical trial of dehydroepiandrosterone in severe systemic lupus erythematosus. Lupus. (1999) 8:181-7. doi: 10.1191/096120399678847588

9. van Vollenhoven RF, Engleman EG, McGuire JL. An open study of dehydroepiandrosterone in systemic lupus erythematosus. Arthritis Rheum. (1994) 37:1305-10. doi: 10.1002/art.1780370906

10. Gordon C, Wallace DJ, Shinada S, Kalunian KC, Forbess L, Braunstein GD, et al. Testosterone patches in the management of patients with mild/moderate systemic lupus erythematosus. Rheumatology. (2008) 47:3348. doi: 10.1093/rheumatology/kem342

11. Petri MA, Mease PJ, Merrill JT, Lahita RG, Iannini MJ, Yocum DE, et al. Effects of prasterone on disease activity and symptoms in women with active systemic lupus erythematosus. Arthritis Rheum. (2004) 50:2858-68. doi: 10.1002/art.20427 of testosterone on pDCs and IFN $\alpha$ production in combination with testosterone-driven myelopoiesis may directly affect MDSC and M2 skewing, while direct binding to the Foxp3 promoter may regulate Tregs and downregulation of BAFF may affect Breg levels and functions in SLE patients and lupus models exhibiting elevated IFN $\alpha$ levels (see Figure 1). While therapies targeting pDCs and IFN $\alpha$, along with autologous Treg treatment, are currently being investigated in SLE patients, MDSCs and Breg are being actively studied as a therapeutic target in a number of cancer treatments but not in SLE. We propose that these cells, in their native immunosuppressive state, should also be evaluated for their therapeutic potential in lupus and other autoimmune disorders.

\section{AUTHOR CONTRIBUTIONS}

All authors listed have made a substantial, direct and intellectual contribution to the work, and approved it for publication.

\section{FUNDING}

This study was partly funded by NIH R01AI118774 (TJ).

12. Chang D-M, Lan J-L, Lin H-Y, Luo S-F. Dehydroepiandrosterone treatment of women with mild-to-moderate systemic lupus erythematosus: a multicenter randomized, double-blind, placebo-controlled trial. Arthritis Rheum. (2002) 46:2924-7. doi: 10.1002/art.10615

13. Nordmark G, Bengtsson C, Larsson A, Karlsson FA, Sturfelt G, Rönnblom L. Effects of dehydroepiandrosterone supplement on health-related quality of life in glucocorticoid treated female patients with systemic lupus erythematosus. Autoimmunity. (2005) 38:531-40. doi: 10.1080/08916930500285550

14. Hartkamp A, Geenen R, Godaert GLR, Bijl M, Bijlsma JWJ, Derksen RHWM. Effects of dehydroepiandrosterone on fatigue and well-being in women with quiescent systemic lupus erythematosus: a randomised controlled trial. Ann Rheum Dis. (2010) 69:1144-7. doi: 10.1136/ard.2009.117036

15. Stahl NI, Decker JL. Androgenic status of males with systemic lupus erythematosus. Arthritis Rheum. 21:665-8. doi: 10.1002/art.1780210609

16. Mok CC, Lau CS. Profile of sex hormones in male patients with systemic lupus erythematosus. Lupus. (2000) 9:252-7. doi: 10.1191/096120300680198926

17. Mackworth-Young CG, Parke AL, Morley KD, Fotherby K, Hughes GR. Sex hormones in male patients with systemic lupus erythematosus: a comparison with other disease groups. Eur J Rheumatol Inflamm. (1983) 6:228-32.

18. Lahita RG, Cheng CY, Monder C, Bardin CW. Experience with 19nortestosterone in the therapy of systemic lupus erythematosus: worsened disease after treatment with 19-nortestosterone in men and lack of improvement in women. J Rheumatol. (1992) 19:547-55.

19. Chan KL, Mok CC. Development of systemic lupus erythematosus in a male-to-female transsexual: the role of sex hormones revisited. Lupus. (2013) 22:1399-402. doi: 10.1177/0961203313500550

20. Pontes LT, Camilo DT, De Bortoli MR, Santos RSS, Luchi WM. New-onset lupus nephritis after male-to-female sex reassignment surgery. Lupus. (2018) 27:2166-9. doi: 10.1177/0961203318800571

21. Santos-Ocampo AS. New onset systemic lupus erythematosus in a transgender man: possible role of feminizing sex hormones. $J$ Clin Rheumatol. (2007) 13:29-30. doi: 10.1097/01.rhu.0000256169. 05087.ad

22. Ocon A, Peredo-Wende R, Kremer JM, Bhatt BD. Significant symptomatic improvement of subacute cutaneous lupus after testosterone therapy in a female-to-male transgender subject. Lupus. (2018) 27:347-8. doi: 10.1177/0961203317734921 
23. Dominguez-Villar M, Hafler DA. Regulatory T cells in autoimmune disease. Nat Immunol. (2018) 19:665-73. doi: 10.1038/s41590-018-0120-4

24. Lundell A-C, Nordström I, Andersson K, Strömbeck A, Ohlsson C, Tivesten A, et al. Dihydrotestosterone levels at birth associate positively with higher proportions of circulating immature/naive CD5+ B cells in boys. Sci Rep. (2017) 7:15503. doi: 10.1038/s41598-017-15836-1

25. Walecki M, Eisel F, Klug J, Baal N, Paradowska-Dogan A, Wahle $\mathrm{E}$, et al. Androgen receptor modulates Foxp3 expression in CD4+CD25+Foxp3+ regulatory T-cells. Mol Biol Cell. (2015) 26:2845-57. doi: 10.1091/mbc.E14-08-1323

26. Frisancho-Kiss S, Coronado MJ, Frisancho JA, Lau VM, Rose NR, Klein SL, et al. Gonadectomy of male BALB/c mice increases Tim-3(+) alternatively activated M2 macrophages, Tim-3(+) T cells, Th2 cells and Treg in the heart during acute coxsackievirus-induced myocarditis. Brain Behav Immun. (2009) 23:649-57. doi: 10.1016/j.bbi.2008.12.002

27. Lapierre P, Béland K, Martin C, Alvarez F, Alvarez F. Forkhead box p3+ regulatory $\mathrm{T}$ cell underlies male resistance to experimental type 2 autoimmune hepatitis. Hepatology. (2010) 51:1789-98. doi: 10.1002/hep.23536

28. Ben ERRD, Prado CH do, Baptista TSA, Bauer ME, Staub HL. Patients with systemic lupus erythematosus and secondary antiphospholipid syndrome have decreased numbers of circulating CD4+CD25+Foxp3+ Treg and CD3- CD19+ B cells. Rev Brasil Reumatol. (2014) 54:241-6. doi: 10.1016/j.rbre.2013.09.001

29. Bonelli M, Savitskaya A, von Dalwigk K, Steiner CW, Aletaha D, Smolen JS, et al. Quantitative and qualitative deficiencies of regulatory $\mathrm{T}$ cells in patients with systemic lupus erythematosus (SLE). Int Immunol. (2008) 20:861-8. doi: 10.1093/intimm/dxn044

30. Yan B, Ye S, Chen G, Kuang M, Shen N, Chen S. Dysfunctional CD4+,CD25+ regulatory $\mathrm{T}$ cells in untreated active systemic lupus erythematosus secondary to interferon- $\alpha$-producing antigen-presenting cells. Arthritis Rheum. (2008) 58:801-12. doi: 10.1002/art.23268

31. Dall'Era M, Pauli ML, Remedios K, Taravati K, Sandova PM, Putnam AL, et al. Adoptive Treg cell therapy in a patient with systemic lupus erythematosus. Arthritis Rheumatol. (2019) 71:431-40. doi: 10.1002/art.40737

32. Wang $\mathrm{T}$, Mei Y, Li Z. Research progress on regulatory B cells in systemic lupus erythematosus. Biomed Res Int. (2019) 2019:7948687. doi: $10.1155 / 2019 / 7948687$

33. Blair PA, Noreña LY, Flores-Borja F, Rawlings DJ, Isenberg DA, Ehrenstein MR, et al. CD19(+)CD24(hi)CD38(hi) B cells exhibit regulatory capacity in healthy individuals but are functionally impaired in systemic Lupus Erythematosus patients. Immunity. (2010) 32:129-40. doi: 10.1016/j.immuni.2009.11.009

34. Iwata Y, Matsushita T, Horikawa M, Dilillo DJ, Yanaba K, Venturi GM, et al. Characterization of a rare IL-10-competent B-cell subset in humans that parallels mouse regulatory B10 cells. Blood. (2011) 117:530-41. doi: 10.1182/blood-2010-07-294249

35. Biotest AG. Phase IIa Study Demonstrates Favorable Safety and Tolerability Profile for Biotest's Monoclonal antibody BT-063 for Treatment of Systemic Lupus Erythematosus (SLE) (Press Release). Dreieich: Biotest AG (2018). Available online at: www.biotest.com/de/en/investor_relations/news_and_ publications/biotest_press_releases/press_detail.cfm?instance_ID $\$=\$ 2768 \&$ cmfaction $\$=\$ x m l d e t a i l . x m l d e t a i l . d e t a i l v i e w \&$ showdetails $\$=\$ 1709363$

36. Menon M, Blair PA, Isenberg DA, Mauri C. A regulatory feedback between plasmacytoid dendritic cells and regulatory $\mathrm{B}$ cells is aberrant in systemic lupus erythematosus. Immunity. (2016) 44:683-97. doi: 10.1016/j.immuni.2016.02.012

37. Ellis TM, Moser MT, Le PT, Flanigan RC, Kwon ED. Alterations in peripheral B cells and B cell progenitors following androgen ablation in mice. Int Immunol. (2001) 13:553-8. doi: 10.1093/intimm/13. 4.553

38. Viselli SM, Stanziale S, Shults K, Kovacs WJ, Olsen NJ. Castration alters peripheral immune function in normal male mice. Immunology. (1995) 84:337-42.

39. Olsen NJ, Gu X, Kovacs WJ. Bone marrow stromal cells mediate androgenic suppression of B lymphocyte development. J Clin Invest. (2001) 108:1697-704. doi: 10.1172/JCI13183

40. Wilhelmson AS, Lantero Rodriguez M, Stubelius A, Fogelstrand P, Johansson I, Buechler MB, et al. Testosterone is an endogenous regulator of BAFF and splenic B cell number. Nat Commun. (2018) 9:2067. doi: 10.1038/s41467-018-04408-0

41. Matsushita T, Kobayashi T, Mizumaki K, Kano M, Sawada T, Tennichi M, et al. BAFF inhibition attenuates fibrosis in scleroderma by modulating the regulatory and effector B cell balance. Sci Adv. (2018) 4:eaas9944. doi: 10.1126/sciadv.aas9944

42. Ramsköld D, Parodis I, Lakshmikanth T, Sippl M, Khademi M, Chen Y, et al. B cell alterations during BAFF inhibition with belimumab in SLE. EBioMedicine. (2018) 40:517-27. doi: 10.1016/j.ebiom.2018.12.035

43. Samotij D, Reich A. Biologics in the treatment of lupus erythematosus: a critical literature review. BioMed Res Int. (2019) 2019:8142368. doi: $10.1155 / 2019 / 8142368$

44. Vukelic M, Li Y, Kyttaris VC. Novel treatments in lupus. Front Immunol. (2018) 9:2658. doi: 10.3389/fimmu.2018.02658

45. Italiani P, Boraschi D. From monocytes to M1/M2 macrophages: phenotypical vs. functional differentiation. Front Immunol. (2014) 5:514. doi: 10.3389/fimmu.2014.00514

46. Schiffer L, Bethunaickan R, Ramanujam M, Huang W, Schiffer M, Tao $\mathrm{H}$, et al. Activated renal macrophages are markers of disease onset and disease remission in lupus nephritis. J Immunol. (2008) 180:1938-47. doi: 10.4049/jimmunol.180.3.1938

47. Labonte AC, Kegerreis B, Geraci NS, Bachali P, Madamanchi S, Robl R, et al. Identification of alterations in macrophage activation associated with disease activity in systemic lupus erythematosus. PLoS ONE. (2018) 13:e0208132. doi: 10.1371/journal.pone.0208132

48. Li F, Yang Y, Zhu X, Huang L, Xu J. Macrophage polarization modulates development of systemic lupus erythematosus. Cell Physiol Biochem. (2015) 37:1279-88. doi: 10.1159/000430251

49. Horuluoglu B, Bayik D, Kayraklioglu N, Goguet E, Kaplan MJ, Klinman DM. PAM3 supports the generation of M2-like macrophages from lupus patient monocytes and improves disease outcome in murine lupus. J Autoimmun. (2019) 99:24-32. doi: 10.1016/j.jaut.2019.01.004

50. Cutolo M, Accardo S, Villaggio B, Clerico P, Indiveri F, Carruba G, et al. Evidence for the presence of androgen receptors in the synovial tissue of rheumatoid arthritis patients and healthy controls. Arthritis Rheum. (1992) 35:1007-15.

51. Routley CE, Ashcroft GS. Effect of estrogen and progesterone on macrophage activation during wound healing. Wound Repair Regen. (2009) 17:42-50. doi: 10.1111/j.1524-475X.2008.00440.x

52. Ma W, Zhang J, Guo L, Wang Y, Lu S, Wang Z, et al. Suppressed androgen receptor expression promotes M2 macrophage reprogramming through the STAT3/SOCS3 pathway. EXCLI J. (2019) 18:21-9. doi: $10.17179 /$ excli2018-1740

53. Zhu W, Zhao Z, Chou F, Zuo L, Liu T, Yeh S, et al. Loss of the androgen receptor suppresses intrarenal calcium oxalate crystals deposition via altering macrophage recruitment/M2 polarization with change of the miR-185-5p/CSF-1 signals. Cell Death Dis. (2019) 10:275. doi: 10.1038/s41419-019-1358-y

54. Becerra-Díaz M, Strickland AB, Keselman A, Heller NM. Androgen and androgen receptor as enhancers of M2 macrophage polarization in allergic lung inflammation. J Immunol. (2018) 201:2923-33. doi: 10.4049 /jimmunol.1800352

55. Zhou B, Zhang H, Su X, Luo Y, Li X, Yu C, et al. Therapeutic effects of a novel BAFF blocker on arthritis. Signal Transduct Target Ther. (2019) 4:19. doi: 10.1038/s41392-019-0051-z

56. Gabrilovich DI, Nagaraj S. Myeloid-derived suppressor cells as regulators of the immune system. Nat Rev Immunol. (2009) 9:162-74. doi: 10.1038/nri2506

57. Ma H, Xia C-Q. Phenotypic and functional diversities of myeloidderived suppressor cells in autoimmune diseases. Mediators Inflamm. (2018) 2018:4316584. doi: 10.1155/2018/4316584

58. Trigunaite A, Khan A, Der E, Song A, Varikuti S, Jørgensen TN. Gr-1(high) $\mathrm{CD} 11 \mathrm{~b}+$ cells suppress B cell differentiation and lupus-like disease in lupusprone male mice. Arthritis Rheum. (2013) 65:2392-402. doi: 10.1002/art. 38048

59. Der E, Dimo J, Trigunaite A, Jones J, Jørgensen TN. Gr1+ cells suppress T-dependent antibody responses in (NZB $x$ NZW)F1 male mice through inhibition of $\mathrm{T}$ follicular helper cells and germinal center formation. $J$ Immunol. (2014) 192:1570-6. doi: 10.4049/jimmunol.1302479 
60. Bird AK, Chang M, Barnard J, Goldman BI, Meednu N, Rangel-Moreno J, et al. Neutrophils slow disease progression in murine lupus via modulation of autoreactive germinal centers. J Immunol. (2017) 199:458-66. doi: 10.4049/jimmunol.1700354

61. Park MJ, Lee SH, Kim EK, Lee EJ, Park SH, Kwok SK, et al. Myeloid-derived suppressor cells induce the expansion of regulatory B cells and ameliorate autoimmunity in the sanroque mouse model of systemic lupus erythematosus. Arthritis Rheumatol. (2016) 68:2717-27. doi: 10.1002/art.39767

62. Bayik D, Tross D, Klinman DM. Factors influencing the differentiation of human monocytic myeloid-derived suppressor cells into inflammatory macrophages. Front Immunol. (2018) 9:608. doi: 10.3389/fimmu.2018.00608

63. Zhan $\mathrm{X}$, Fang $\mathrm{Y}, \mathrm{Hu} \mathrm{S}, \mathrm{Wu} \mathrm{Y}$, Yang $\mathrm{K}$, Liao $\mathrm{C}$, et al. IFN- $\gamma$ differentially regulates subsets of $\mathrm{Gr}-1(+) \mathrm{CD} 11 \mathrm{~b}(+)$ myeloid cells in chronic inflammation. Mol Immunol. (2015) 66:451-62. doi: 10.1016/j.molimm.2015.05.011

64. Ji J, Xu J, Zhao S, Liu F, Qi J, Song Y, et al. Myeloid-derived suppressor cells contribute to systemic lupus erythaematosus by regulating differentiation of Th17 cells and Tregs. Clin Sci. (2016) 130:1453-67. doi: 10.1042/CS20160311

65. Wang Z, Zhu F, Wang J, Tao Q, Xu X, Wang H, et al. Increased CD14+HLADR-/low myeloid-derived suppressor cells correlate with disease severity in systemic lupus erythematosus patients in an iNOS-dependent manner. Front Immunol. (2019) 10:1202. doi: 10.3389/fimmu.2019.01202

66. Vlachou K, Mintzas K, Glymenaki M, Ioannou M, Papadaki G, Bertsias GK, et al. Elimination of granulocytic myeloid-derived suppressor cells in lupus-prone mice linked to reactive oxygen species-dependent extracellular trap formation. Arthritis Rheumatol. (2016) 68:449-61. doi: 10.1002/art.39441

67. Jefferies CA. Regulating IRFs in IFN driven disease. Front Immunol. (2019) 10:325. doi: 10.3389/fimmu.2019.00325

68. Zhuang H, Szeto C, Han S, Yang L, Reeves WH. Animal Models of Interferon Signature Positive Lupus. Front Immunol. (2015) 6:291. doi: 10.3389/fimmu.2015.00291
69. Ryffel B, Car BD, Gunn H, Roman D, Hiestand P, Mihatsch MJ. Interleukin6 exacerbates glomerulonephritis in (NZB x NZW)F1 mice. Am J Pathol. (1994) 144:927-37.

70. Mihara M, Takagi N, Takeda Y, Ohsugi Y. IL-6 receptor blockage inhibits the onset of autoimmune kidney disease in NZB/W F1 mice. Clin Exp Immunol. (1998) 112:397-402. doi: 10.1046/j.1365-2249.1998.0 0612. $\mathrm{x}$

71. Berghöfer B, Frommer T, Haley G, Fink L, Bein G, Hackstein H. TLR7 Ligands induce Higher IFN- $\alpha$ production in females. J Immunol. (2006) 177:2088-96. doi: 10.4049/jimmunol.177. 4.2088

72. Kanda N, Tsuchida T, Tamaki K. Testosterone suppresses anti-DNA antibody production in peripheral blood mononuclear cells from patients with systemic lupus erythematosus. Arthritis Rheum. (1997) 40:1703-11. doi: 10.1002/art.1780400921

73. Wang JP, Zhang L, Madera RF, Woda M, Libraty DH. Plasmacytoid dendritic cell interferon- $\alpha$ production to R-848 stimulation is decreased in male infants. BMC Immunol. (2012) 13:35. doi: 10.1186/14712172-13-35

Conflict of Interest: The authors declare that the research was conducted in the absence of any commercial or financial relationships that could be construed as a potential conflict of interest.

Copyright (c) 2020 Jones and Jørgensen. This is an open-access article distributed under the terms of the Creative Commons Attribution License (CC BY). The use, distribution or reproduction in other forums is permitted, provided the original author(s) and the copyright owner(s) are credited and that the original publication in this journal is cited, in accordance with accepted academic practice. No use, distribution or reproduction is permitted which does not comply with these terms. 